\title{
Interpretation of Technological Innovation Essence in View of Cultural Philosophy
}

\author{
Peng $\mathrm{Li}^{1}$, Rui Wang ${ }^{2}$
}

1) School of Humanities and Law, Northeastern University, Shenyang, Liaoning, China

2) School of Humanities and Law, Shenyang University of Technology, Shenyang, Liaoning, China

\begin{abstract}
Cultural turn of technological innovation (TI) embodied how to formate the investigation of technology in the interaction of various factors for Social Shaping of Technology. The action TI is taken as a kind of ideological practice, studying mode of evaluating TI behaviors from cultural integrity, which revealed that technological innovation is historical accumulation and representation of humans innovation practice, and is also essence of objectification of TI's subject internal essential power in new constructing man' . It is a comprehensive understanding of technology innovation is a part of the social culture and an agent of social and cultural development.
\end{abstract}

Keywords - TI; cultural philosophy; essence

\section{从文化哲学的视角解读技术创新本质}

\author{
李鹏 $^{1}$ 王睿 $^{2}$ \\ 1) 东北大学文法学院, 沈阳, 辽宁, 中国 \\ 2)沈阳工业大学文法学院, 沈阳, 辽宁, 中国
}

摘 要 技术创新研究的文化转向体现了技术的社会形成理论对技术如何在多种因素的相互作用中得以形成的考察。这种将技术创新活 动视为一种认知实践, 从文化整体性出发评价技术创新行为的研究方式, 揭示了技术创新既是人类创新实践的历史积累和表征, 又是对人的 内在价值和生存方式的新构筑的技术创新主体内在本质力量对象化的本质, 实现了对既是社会文化的一个组成部分, 又是社会文化发展的一 个动因的技术创新的全面理解。

关键词 技术创新; 文化哲学; 本质

当一个社会由于技术创新的成功导致其在科技和经济发 展水平上占有很大优势的时候, 与之相伴随的文化便把能够 激发成员的创造潜力, 乐于参与的态度和协调一致的行为等 技术创新价值观念和行为模式内化于社会文化中。在这个意 义上，技术创新过程成为了一个开发利用“新技术”而建构“新 社会”的过程, 究其根本, 是技术创新主体内在本质力量的对 象化。

\section{1. 技术创新是人类创新实践的历史积累和表征 \\ 与技术发明采取理论形式、技术或样品形式存在不同，} 技术创新要使技术发明进入物质资料生产和社会关系生产的 领域, 通过市场产生新的效用, 为人们所使用和接受。在这
个过程中, 技术创新所具有的文化特征作为一种创新资源和 生产要素, 融进技术创新活动及其成果中, 是技术创新实践 的历史积累和表征。

\section{1 技术创新蕴涵着主体价值观与社会文化的互动}

技术创新的最终产物是以对象性的技术物的形式而存 在, 并展示着创新主体异于他人的创造能力和精神品质。其 具体的存在方式是由技术创新自身的客观形成规律及技术创 新的主体选择决定的, 所以技术创新必然具有技术创新的客 观属性和选择主体的文化表征。由于技术创新的各个阶段都 是开放的, 与外界有物质和信息的交换, 因而, 文化也就可 以以自己特有的方式对技术创新起到内在的、无形的推动作

国家社会科学基金项目支持 (资助号：12CZX019); 辽宁社科基金项目支持 (资助号：L09DZX018); 辽宁省高校优秀人才计划支持 (资 助号: WJQ2012005) 
用。于是, 技术创新不仅要求人们的规范和观念与之相适应, 也要求形成新的社会生产组织形式以做出保证。没有文化规 范体系中新的观念、规范、组织形式与技术创新行动相适应, 技术创新行动就不会在相应的企业、行业、社区或国家中转 变为生产力或竞争力。正如彼得.科斯洛夫斯基所说: “技术并 不只是物质现象, 而且也是精神现象。它不是外在于文化的, 它本身也正是社会发展中文化作用的要素。技术是人的精神 活动的世界。它不像自然那样是“自己’形成的。技术所包含的 知识不是由外在世界引起的, 而是由人发现、揣摩、“构想, 出来的。”[1]按照技术创新系统的观点来遵循技术创新的存 在领域, 技术创新是其文化要素作用于技术系统的结果的展 现。在这里, 技术创新的主客体要素的关系不是原先设定的, 而是在技术创新过程中确立的。也就是说, 技术创新不是存 在于主体改造客体的系统中, 而是存在于认识活动、行动和 劳动中, 社会文化因素成为建构技术创新的主导因素。

\section{2 技术创新具有人的社会化、技术的社会化属性}

技术创新作为人的生活和行为方式的基础之一，其本质 在于融入了人的文化本质即“人性”。技术创新的创建与发展 体现了技术界定文化的巨大力量。但是，技术对文化的界定 并不意味着技术就能超越广阔的文化视域, 从本源来看, 技 术创新仍旧是文化视野中的技术创新, 文化终究是技术创新 产生、发展的源泉、母体, 具有人的社会属性。此外, 技术 创新的文化凝聚必须通过技术物加以表征。因为人的本质力 量只有通过技术, 使创新客体的规定成为创新主体的内在本 质力量, 才能展示创新主体在技术创新过程中的能动本质。 当然, 技术并非是实现人的目的的单纯手段或工具本身, 而 是人把已经掌握了的自然规律能动地整合到自己的目的性预 期中来的一系列过程及结果; 而从其结果看, 它本身就是人 的目的性预期与其相应手段或工具的实现了的统一体。在这 个意义上, 技术就成为人的意志的物质形式, 即人类有目的 引起自然界定向变化的手段与方法。[2]

\section{3 技术创新是创新主体精神存在方式的凝聚}

文化是历史地凝结成的稳定的生存方式,既包括物质方 面, 也包括精神方面。技术创新主体在特定的活动规制下, 以一种不同于以往实践主体的精神气质存在着。技术创新活 动的风险性和不确定性也需要创新主体能够有将目标进行下 去的信念、勇气和排除烦扰的能力。因此, 技术创新体现了 创新主体的企业家精神、执着精神等观念品质。伊诺斯详细 研究了 20 世纪前半期在石油精炼工艺中的各项重大创新认 为: 从我们所知的证据来看, 创新者真正的动机只能假定为
好奇心与创造性的结合体。创新者渴望去满足他们观察到的 实际需要, 希望自己的技术成就和由此而产生的经济利益能 得到他人的赏识和尊重。这些似乎是比贪婪更重要的特性。 [3]巴萨拉也认为, “技术创新过剩当然并非经济需要促成。技 术专家创造它们是因为从想象本身就能获得乐趣, 即使不图 其实用价值也图其在可能范围内运作自如的乐趣。”[4]可见， 人的创造性的发挥和个性的发展与其本身要求创造的愿望相 关, 人们要求创造的愿望越强烈, 技术创新动力越大, 技术 创新的成果越丰富, 技术创新的文化价值才越突出。

\section{2. 技术创新是对人的内在价值和生存方式的新构筑}

技术创新主要反映人与自然的矛盾, 包括目的与手段的 矛盾、主观与客观的矛盾、观念与现实的矛盾。人的主观能 动性和创造性不仅表现在对上述矛盾的认识与感悟, 而且更 主要地表现在对矛盾同一性的寻求, 并通过文化无形的、潜 移默化的作用, 实现对人的内在价值和生存方式的构筑, 集 中表现在三个方面:

\section{1 形成技术创新主体间的共识}

技术创新的实施需要综合考量技术、经济、文化、宗教 以及政治的各种背景对其的接纳程度, 并通过不同技术创新 主体的融合, 实现一种客观的有效性。创新主体通过共同的 技术创新活动, 或在不同的领域为一个技术创新目标工作, 形成共同的生活体验, 感受着相同或相似的经验世界。人们 的价值观念和行为方式因此受到技术创新活动的形塑, 表现 为一种以技术创新为特征的生存方式, 在许多方面达成共识。 2.1.1通过对社会的调试, 使公众形成积极的社会认知来接受 技术创新

技术创新作为强势性和普遍性的力量染指人类历史根基 并招致了前所未有的价值选择的变迁与困惑, 而人在形而上 的意义上是价值性的存在, 人正是依据主客两个尺度进行价 值选择, 从而彰显着人之为人的类本质。人也恰恰就是在技 术进步与价值选择的不断变迁中推动着人类社会的前进。即 使是从市场的观点看, 人的技术创新活动也不只是市场交换 内容的创新, 还包括了交换方式与市场本身的创新。这就使 技术创新进入了社会创新, 在更为完整的意义上理解对象化。 也就是说, 技术创新的对象化范围是与技术创新的活动范围 相对应的, 是对象化的系统, 而不仅仅是新产品的问世。这 样一来, 公众或消费者在接触和使用技术创新产品的过程中, 可以形成相同或相似的生活体验, 并随着技术创新产品的效 用性、便利性等功能作用的发挥, 在公众产生创新认同, 形 成一种有利于创新的社会氛围。 
2.1.2通过对创新模式的调节, 使创新主体以合作的方式进行 技术创新

通常意义上, 同质性团队的创新性不可能优于其中最具 创造力的个体, 但在异质性的团队中, 团队的创新成果会优 于个体创新成果的总和。换句话说, 如果团队的创造力比不 上个体的创造力, 那么团队就必须通过放权、增加成员的自 由度来提高创造力。以此鼓励成员更坚定地坚持自己的想法, 为团队做出重大贡献。否则, 个体可能会因为担心遭到其他 成员的反对, 而不敢有所作为[5]89。可见, 团队合作的创新 方式在技术创新中具有举足轻重的作用。技术创新中基础研 究、成果转化、产品开发、产品营销等几个过程的完成, 必 须以一个团队为实施主体, 以团队合作为保障。因此, 通过 经常性的创新合作, 能够塑造创新主体合作的行为模式, 体 现出技术创新的文化调节功能。

\section{2 形成一种创新主体间的新关系}

在人所独有的自由自觉的创造性的本质活动中, 形成了 两种基本的关系：一是主体一客体结构或主客体关系; 二是 主体间性结构或主体与主体间的交往关系。这双重结构的展 开, 从历时态看, 是人的历史或实践总体的演进, 从共时态 看, 则是人的世界或人类社会的建构[6]。换言之, 人的技术 创新活动不仅生产出技术产品, 而且生产出生产技术产品的 行为关系，不仅生产出技术创新主体同其产品的关系，而且 生产出创新主体之间的关系，即成员间的彼此信任、彼此间 的宽容、以创新为目标的团队合作。

2.2.1成员间的彼此信任。

创新过程的不同阶段需要整合, 各种不同的力量需要整 合, 研究团队的不同成员也需要整合, 只有这样, 才能形成 一个忠诚于同一个目标的创新集合体。如果在技术创新活动 中, 创新主体不能相互信任地合作, 或者彼此间的利益冲突 不能调和, 那么创新活动就无法进行和持续下去。因此, 技 术创新需要成员间彼此间的高度信任, 进而形成内心强烈的 共同的信仰、愿望、价值和规范。这种信任同时反映到行为 实践和器物层, 通过人们的行为表现出来。另外, 技术创新 的参与者必须是诚实、有能力、可靠、忠诚和宽以待人的[7]。 道尔蒂认为, 文化对创新的阻碍源于难以改掉的常规习惯和 理解上的困难。从常规习惯上看, 无论是特地组织, 本能地 发展, 还是积极的行为, 过程和信息, 都是促使职员去关注 他们自身的任务和职责。结果, 当解决方案超过了个人的职 责范围时, 阻碍也就产生了, 这是创新过程本身所固有的集 体的冲突。因此, 所有参与者必须为了一个目标去工作 [8]。 也就是说, 技术创新对于组织成员进行自觉的或主动的合作
鼓励, 会在很大程度上刺激和激励技术创新活动, 并将官僚 主义的思想拒斥在外。

\subsection{2彼此间的宽容。}

宽容是对于异己的包容。以硅谷为例, 技术创新的宽容 性主要体现在三个方面: 一是对异己的宽容。硅谷凝聚着有 着不同的道德意识、不同风俗习性、不同思维方式、来自世 界各国的高科技产业优秀人才。二是对失败的宽容。硅谷的 文化不仅给予成功者敬意, 失败者也被社会所接受和宽容。 在硅谷, 由于高科技产业的巨大风险, 创业过程中的失败者 永远多于成功者。在这里, 真正的英雄是那些曾经失败但后 来又获得成功的人。三是对背叛的宽容。硅谷以其超乎寻常 的快速跳槽而著称。早在1970年代, 硅谷的电子公司平均每 年的雇员变动为 $35 \%$, 而小公司则高达 $59 \%$ 。不同的技术人才, 在各个公司频繁的流动过程中, 其所拥有的技术资源可以在 各公司间形成共享, 加之各公司技术人员相互间常有着广泛 的非正式的交流，使知识、信息和技术能够在不同的公司间 快速传播, 便于整个硅谷地区在其劳动力的高度流动中受益。 在硅谷宽容的氛围里, 人们对企业的忠诚变成了对事业的忠 诚。

2.2.3创新型的团队合作。

对于不同的国家而言, 创新获得成功所需要的执著程度 各不相同。创新往往是一个对峙和合作的过程。企业内部, 新技术需要与传统技术对峙。面对传统技术, 只有研究团队 的执著可能还不够, 团队必须寻求高层管理者以及对创新抱 有信心的其他部门的合作。在市场中, 创新往往要面对其他 竞争者的传统产品, 往往要首先挑战消费者的传统消费模式。 它能否取得成功, 主要依赖于创新产品能否快速地获得早期 采用者或领先用户的合作 [5]95。不同技术共同体的交流可以 共享失败的经验, 以减少技术创新过程中的不确定性。因此 创新团队必须有良好的内部交流。技术创新的对象构建是一 个复杂活动, 涉及多个层面, 并肩负着高度专业化的任务, 需要通过成员彼此之间的分工协作而实现, 仅仅依靠执着是 不足以使创新获得成功的。

\section{3 形成创新主体的共同信念和精神}

人们借助文化的标识符号系统进行着交往、交流和社会 博亦, 使每个人的现实行为背后都有一种潜在的、难以言说、 但为大家所共享的观念性的知识或意义的逻辑坐标在起着作 用。文化的群体控制功能, 向横向拓展, 能够渗透到社会生 活的各个领域, 通过支配人们的头脑来影响人们的社会实践 活动; 向纵向蔓延, 能够深入到人们意识的潜层次中去, 化 作主体内在、自觉和本能的行为。 


\subsection{1坚强信念}

信念是一种对从事的实践的肯定和确认，人们由于有了 信念的支撑可以为此用尽自己最大的能力和力量, 甚至是付 出生命的代价。历史上无数仁人志士舍生取义的事例都能够 证明这一点。在技术创新过程中，技术的、过程的、市场的、 结果的等诸多的不确定性, 使其充满了创新的风险。人们在 进行技术创新的过程中必须要创新才能够成功、必须要有成 功的坚强信念, 才能将创新进行到底。“可以预见的是, 当创 新成为一种社会特征时, 人们倾向于把自身看作是有创造力 的, 即便他们实践上并没有创造力。这意味着工程师认为工 程师是富于创造的, 销售员认为销售员是富于创造的。”[9] 2.3.2科学精神

科学精神鲜明的客观真理性、可检验证实性、逻辑系统 性以及累积发展性是技术创新活动的重要依托。斯坦纳在论 证科学和创新的关系时指出, 1969年, 格林伯格谴责保护科 学的沙文主义、排外主义和福音主义的正当性的科学家。同 年, 麦厄斯和马奎斯著名的研究报告中, 大部分使用了创新 者是个人知识而不是人类的研究知识。仅 $8 \%$ 的创新信息来自 实验和计算, 7\%来自像杂志等出版物。这些发现表明, 创新 不是传统的“科学的”活动。1972年, 另一个主要的创新研究 重申, 科学不是创新的主要贡献者。这项研究的合作者之一 指出, 可能科学不是创新之父, 但它在过去一直匿名地向创 新寄送礼物。此后的二十年之后, 创新学者仍认为有必要去 重申这一点[10]。20世纪, 信息处理技术成为中心课题, 电 子计算机、雷达、集成电路等相继得到开发, 电子数据处理 技术朝向大容量、小型化和高速度发展。这是最典型的直接 应用科学原理或与科学原理、科学方法密切相关的技术。在 此技术的背后, 有其严密的科学理论或体系联系着、支撑着 技术活动。要是没有划时代的重大的科学发现和理论推进, 就几乎不可能有划时代的技术发明、技术进步和技术革命 [11]。

\subsection{3创新精神}

在产生想法和发现新物质的过程中, 个体是创新成功的 主要因素。实际上, 在研发阶段, 团队为解决研发问题所进 行的讨论会比个体的思考更有益于创新成功。洪科在对资本 投资失败的分析中指出: 原创性的灵感和构想能否被整合到 最终的创新项目中去, 是决定创新成败的重大因素。创新团 队的整合包括: 需对异质性背景的成员进行整合; 需对来自 不同学科的成员进行整合; 需对来自不同国家和文化背景的 成员进行整合; 需对拥有不同知识的成员进行整合 [5] 99 。此 外, 技术创新有助于增加企业培训及教育投入, 使创新精神 能够在更广阔范围传播。技术创新对个人的内在制约被外在
力量所推动, 通过培训和教育方式在代内和代际之间进行传 递。创新精神通过文化传递被他人及新一代有选择地接受, 进而保证了技术创新的连续性。

\section{3. 结论}

技术创新既是一种技术经济活动, 也是人发挥创造本性 将技术的本质和客观实在性通过人的社会性实践整合起来的 过程, 是对不同时代文化精神和文化机理的直观反映。将技 术创新活动视为一种认知实践, 从文化整体性出发评价技术 创新行为, 了解技术与社会的深层互动, 既体现了技术的社 会形成理论对技术如何在多种因素的相互作用中得以形成的 考察, 又体现了技术创新研究的文化转向。可以探寻更合理 的技术创新发展方向, 重新审视技术创新与生俱来的功利主 义弊端, 解决从整体性出发的技术创新认识论问题, 实现科 学文化与人文文化的融合与统一。

\section{参考文献（References）}

[1] P. Koslowski. Postmodernism Culture-The social and cultural consequences of Technological Development. Mao Yihong. Beijing: Central Compilation \& Translation Press, 1999: 2.

[2] Xiao Feng. On the social shaping of Technology. Social Sciences in China, 2002 (6): 68-77.

[3] Charles Singer Editor. A History of Technology VI. Jiang Zhenhuan, Zhao Yuqin, the main translation. Shanghai: Shanghai scientific and Technological Education Publishing House, 2004: 19.

[4] George Basler. Technology development history. Zhou Guangfa, translation. Shanghai: Fudan University press., 2000: 75.

[5] Berlin Institute of science and technology. Culture and Technical Innovation. Wu Jinxi et al. Beijing: Intellectual Property Press, 2006.

[6] Yi Junqing. The fifteen Culture Philosophy. Beijing: Peking University Press, 2004: 30-31.

[7] Jassawalla, Avan R., Hemant C. Sashittal. The DNA of cultures that promote product innovation. Ivey Business Journal, 2003: $1-6$.

[8] Gerben van der Panne, Cees van Beers,Alfrde Kleinknecht. Success and failure of innovation: a literature review. International Journal of Innovation Management, 2003, 7 (3): 313.

[9] Zhuang, Lee, David Williamson, Mike Carter.Innovate or liquidate are all organizations convinced? A two-phased study into the innovation process. Management Decision, 1999: 57.

[10] Carol, J., A Steiner. Philosophy for innovation: the Role of unconventional individuals in innovation success. Journal of Product Innovation Management, 1995 (12): 433.

[11] Meng Jianwei. Humanistic dimension of Technology. Philosophical Trends, 2002 (5): 15. 